\title{
NHI consensus: fix the existing system or risk failure
}

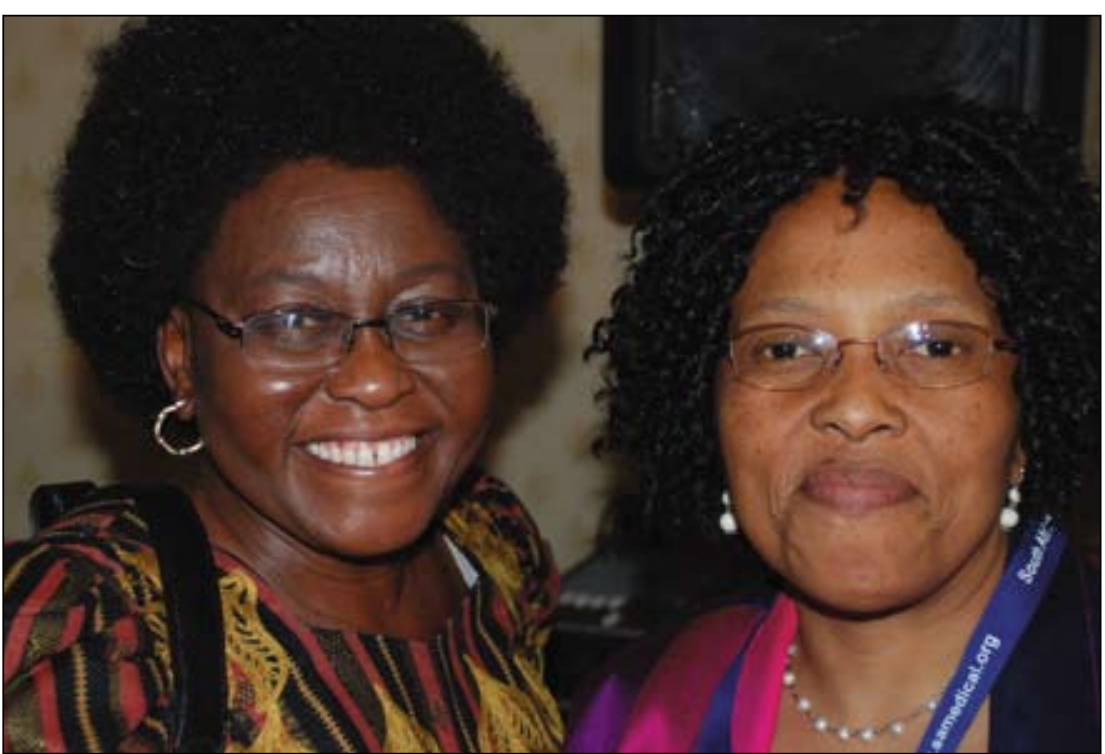

Dr Olive Shisana, NHI task team leader (left) and Precious Matsotso, Director General of Health.

Picture: Chris Bateman

It's not often that 360 doctors of varying disciplines, anxiously awaiting the birth of a much-fêted infant, agree on the diagnosis and urgent treatment of its severely ailing mother. That's what happened at the South African Medical Association (SAMA)'s prenatal 'check-up' of the impending National Health Insurance (NHI), at Emperor's Palace in Gauteng early this October. Everyone, from NHI midwives Dr Aaron Motsoaledi (national health minister) and Dr Olive Shisana (its chief nurse), to individuals like social security economist Alex van den Heever (who at best fears a failure to thrive), believes the diagnosis of the health care system upon which an effective NHI will depend is blindingly obvious. They also agreed on a 10-point treatment plan for the ailing matriarch (one aspect of which is the NHI, aimed at providing vital health equity and access for all). That left only one real question: Does 'Mama Nzantsi' have the human and financial capital, let alone the management capacity, to carry, give birth to and then nurture this NHI child to maturity?

That left only one real question: Does 'Mama Nzantsi' have the human and financial capital, let alone the management capacity,

to carry, give birth to and then nurture this NHI child to maturity?
That's where the core debate lay over the two-day conference, replete with argument, debate, murmuring and dissent - essential ingredients for the tailoring of an appropriate and effective NHI - if the midwives keep their promise to study SAMA's facilitated input. Motsoaledi found no dissenters when he diagnosed the cause of the malaise as 'a destructive, unsustainable, expensive curative health system', where, he quipped, 'each of the 50 million of us seem entitled to one major disease per year'. His consensual 10-point treatment plan highlighted what is wrong, pointing to a historical lack of leadership or social compact with all role-players (now being addressed, inter alia, through an ambitious public/private counselling and testing campaign aimed at reaching 15 million people by June next year). Motsoaledi admitted that hospital hygiene and infection control are 'dismal', that there is a dire lack of minimum standards, that the management of facilities and finances is abysmal, and openly complained that the planning and development of human resources had 'gone completely haywire'.

\section{Aaron's treatment plan}

$\mathrm{He}$ said poor infrastructure was being addressed via the renovation of five major hospitals, the cost of which would exceed the construction price for all Soccer World Cup stadia. The HIV/AIDS pandemic finally had a realistic and comprehensive plan, with targets, best practice treatment protocols, major financing and drug supply cost containments and improved drug supply chain management tools. There would also be a 'pragmatic rationalisation' of some 60000 community development workers while the overall drug policy, acquisition, supply chain and expiry/wastage were being probed and overhauled. Research, or the dire lack of it, was also on the 10-point agenda.

Expanding on several points, Motsoaledi said the nursing curriculum was 'completely messed up' when colleges were closed down and the decision taken in 1986 to only train via universities, resulting in 'an army with commanders and no riflemen' (one estimate is 98000 professional nurses to 35000 enrolled nurses). Eight medical schools had produced 1200 doctors for the past 8 years, further aggravating the shortage and illustrating the dire need for a ninth. Keen to illustrate just how far his government had moved from the denialism and obfuscation of the Mbeki/TshabalalaMsimang era, Motsoaledi said the overall plan was aimed at countering a forbidding fourfold epidemic of HIV/TB, maternal, newborn and child mortality and morbidity, non-communicable diseases, and injury and violence. 'Most other countries are spending less for better health outcomes. Our spending has not kept pace with the disease burden. Is this money or mismanagement? Mismanagement is clear, but spending also declined at a time when our burden of disease was increasing.

He said 'Bantu education' had left the country' 'with a monster in our midst', where most locals compared poorly with residents of other SADC countries.

He said 'Bantu education' had left the country 'with a monster in our midst', where most locals compared poorly with residents of other SADC countries. Worse, South Africa had $17 \%$ of the world's HIV pandemic (with just $0.7 \%$ of the global population) -23 times the global average. TB prevalence was the world's worst at seven times the global average, while HIV/TB co-infection stood at $73 \%$. Motsoaledi described the maternal, newborn and child mortality and morbidity figures as 'embarrassing', having 'soared 


\section{Schools' average maths score, SA vs. other SACMEQ countries}

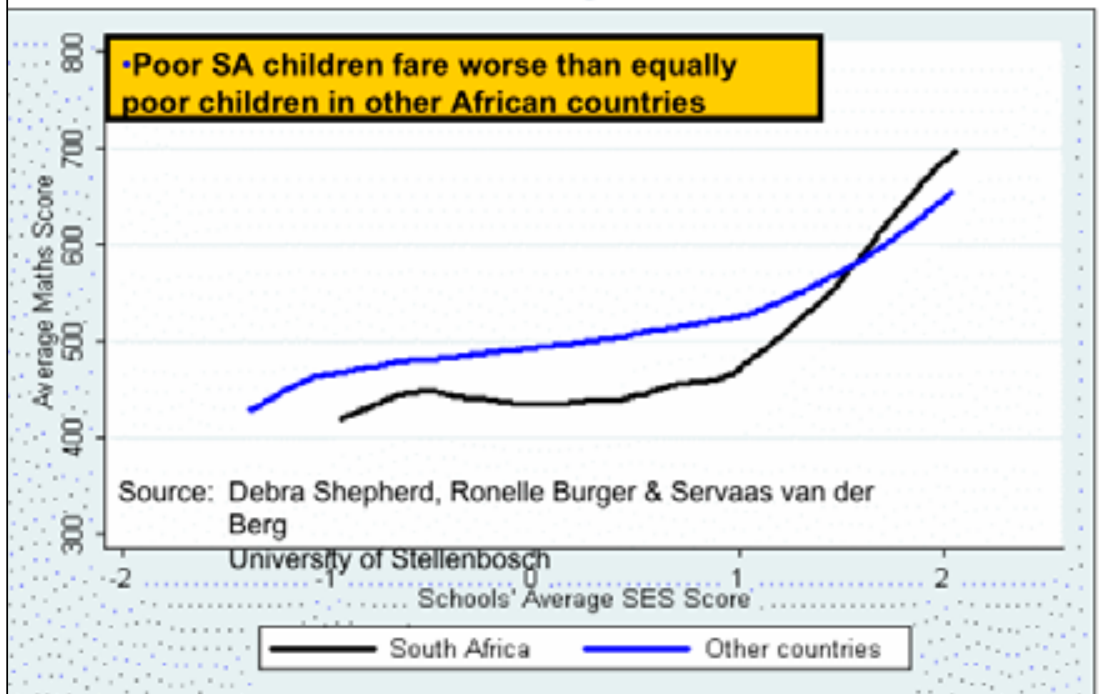

Source: Alex van den Heever, presentation to SA Medical Association NHI conference, Emperors Palace, Gauteng, 8 October 2010.

way above the Millennium Development Goals bar when other countries are showing improvements.' 'Falling pregnant, being born or living for the first five years is very risky in South Africa, he said, adding that the success of any country was measured by the number of children who died in childbirth or by the age of five. While South Africa met the World Bank's criteria for a country's survival (an independent judiciary, bank security and security of tenure), its Gini coefficient was the world's worst. One World Bank advisor confided to him: 'Solve your gap between the rich and poor and you'll achieve stability'. Motsoaledi said this further emphasised how important the speedy entrenchment of an NHI system was. He and his new Director General, Precious Matsotso, rebuffed suggestions from the floor that '10-point action, not a 10 -point plan' was needed, citing many ongoing rehabilitation measures. Other delegates accused them of building the NHI on romantic idealism rather than pragmatism steeped in reality.

\section{Redirect resources and ID cost drivers - Shisana}

Dr Olive Shisana, chairperson of the 23-person NHI Ministerial Advisory Task Team, said the project's success and incremental roll-out from 2012, when it would cost R128 billion (nearly tripling to R375.5 billion by 2025), would be built on the 'redirection' of resources via stringent budget measures and identification of cost drivers. The biggest systemic cost drivers at present were ARVs (where much greater purchasing efficiencies could be achieved), the National Health Laboratory Service (NHLS) and equipment. 'Unless we address these three (before 2012), it will be very difficult to start the process', she admitted in response to a question on how the current R11 billion shortfall on the 2012 NHI budget would be addressed. Shisana said probes into the health care staffing crisis showed a disproportionate increase in management and administrative structures at national and provincial level. Her team was working with the Colleges of Medicine and the Committee of University Deans to establish how many doctors and specialists were needed (let alone how to address the current $35 \%$ shortfall on existing public sector posts). Nursing colleges would shortly be opened and a better balance between academic and bedside training strived for. Supportive legislation needed passing, minimum standards for compliance and subsequent gradual NHI hospital accreditation was being completed while management standards were being drastically improved with a hospital-byhospital audit of managers and CEOs. She added: 'We must make sure we have sufficient health professionals capable of doing the work they are supposed to - and ensure a change of attitude and clinical standards across the board in management. We'd like to see public hospital facilities become just as good as private.'

Several speakers at the conference and commentators afterwards questioned the assumptions upon which the NHI is being built. Economist and ad hoc government advisor, Alex van den Heever, parodied the NHI committee's commitment in 1995 to the rapid establishment of a district health system which it then claimed was 'of the highest priority and at the core of the entire health strategy'. Added to this, a White Paper in 1997 outlined a primary health care package that put communities at the centre of delivery, electing people to advocate for them on health matters. Instead, what the country got (6 years later in the National Health Act) were 6 people ( 1 representing the provincial health minister and 5 nominees from relevant municipal councils) and 3 - 5 people drawn from metropolitan, district and local municipal councils.

\section{The biggest systemic cost drivers} at present were ARVs (where much greater purchasing efficiencies could be achieved), the National Health Laboratory Service (NHLS) and equipment.

'Unless we address these three (before 2012), it will be very difficult to start the process,' she admitted in response to a question on how the current R11 billion shortfall on the $2012 \mathrm{NHI}$ budget would be addressed.

\section{Reform track record bodes ill - Van den Heever}

'Reform promises don't mean a lot if you've seen them all before. The district health system is at the core. None of what was proposed there has happened. It's very easy to promise grand things - the reality will probably be very different,' he predicted. Van den Heever said South Africa had a major 'performance problem' in the delivery of public services in general with education matching health, 'which strongly points to a generalised problem with governance and accountability'. This 'inconvenient evidence' was being largely ignored in current debates. When it came to the financing of the health sector, no peer developing country spent $8 \%$ of its GDP (envisaged for South Africa, up from the current $3.4 \%$ ) through the public system. Tony Twine, a top economist with Econometrix (a highly regarded private analysis and planning consultancy), questioned the NHI budgeting assumption that South Africa would achieve an economic growth rate of over 7\% per year for 13 consecutive years. Growth of between 3.5\% and $4.5 \%$ was far more realistic, meaning that health care expenditure would consume between $22.8 \%$ and $28.2 \%$ of all government spending and up to $8.5 \%$ of GDP by 2025 . 'If 


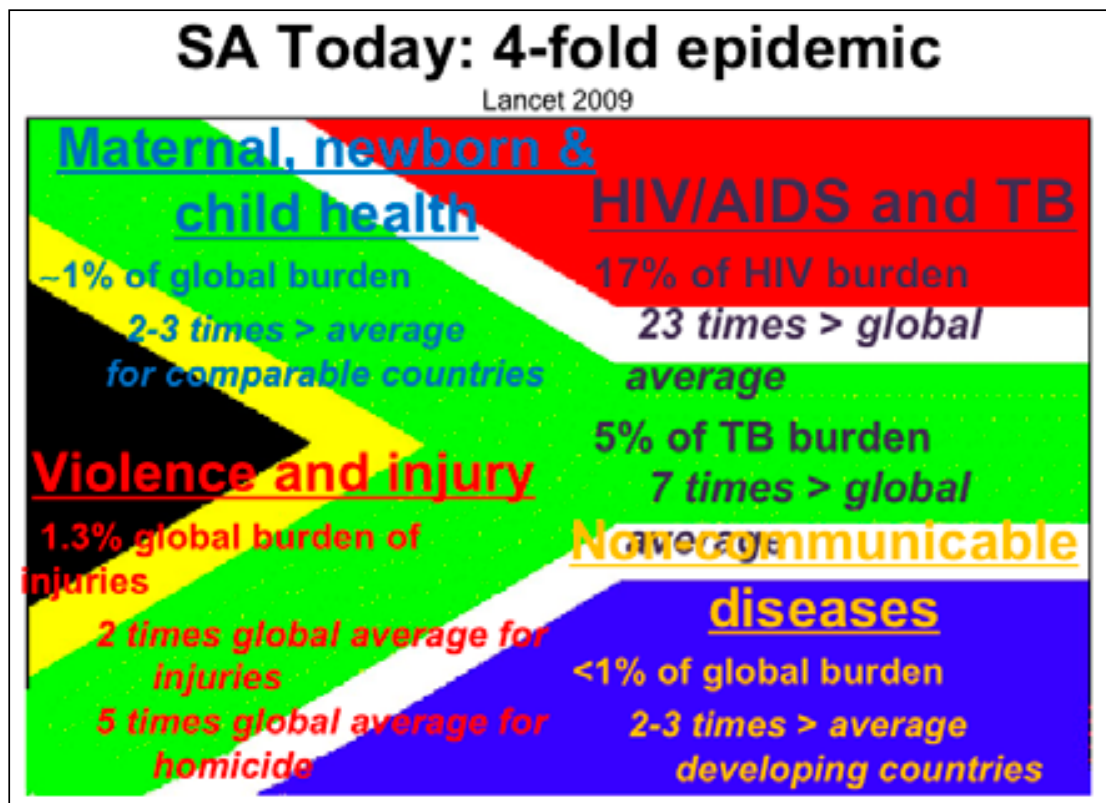

Source: Professor Jannie Hugo, presentation to SA Medical Association NHI conference, Emperors Palace, Gauteng, 8 October 2010.

GDP growth remains as low as $2 \%$ per year, as it did for 20 years between 1975 and 1995, the NHI would simply be unaffordable, he warned, adding that his realistic prediction of $3.5-4.5 \%$ might be affordable but would create deep friction with other high-priority government targets (education, housing and productive infrastructure). Twine said increasing the general tax load (as proposed) 'too much' would simply weigh down the economy, limiting growth and job creation. In a seeming riposte to Van den Heever's district health criticisms, Shisana said her team had based their proposals on a systematic review of 85 studies of primary health care models globally. They

'Reform promises don't mean a lot if you've seen them all before.

The district health system is

at the core. None of what was proposed there has happened. It's very easy to promise grand things - the reality will probably be very different,' he predicted.

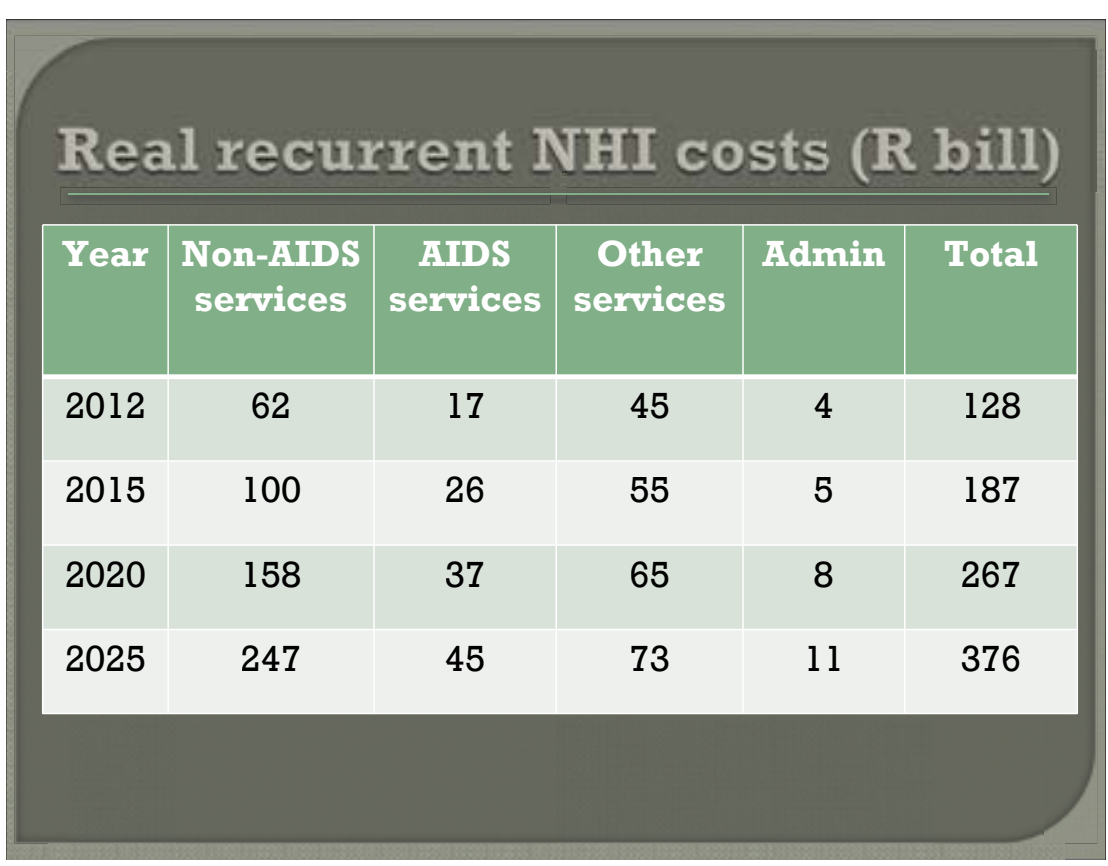

Source: Dr Olive Shisana, presentation to SA Medical Association NHI conference, Emperors Palace, Gauteng, 8 October 2010. then cherry-picked those that had improved delivery. Structure, process and outcomes were central and under-served areas would be contracted first, with decentralisation and locally developed plans a key element. 'Patient advocacy will be critical - we want to avoid a situation like in the United Kingdom where $10 \%$ of patients who visit facilities end up with the wrong care, she added.

\section{Olive gets huffy with Alex}

Dr Shisana's obvious annoyance with Van den Heever's critique drew loud interjections and murmurs from her audience when she described his presentation as 'full of holes'. 'You're not trained in public health and it's difficult to interpret what you show', she added, pointing to the success of the recent Soccer World Cup as an example of what South Africans could do when they chose to work collectively. She said the buying power of the NHI fund would be 'massive', thus cutting costs while various complementary means of meeting the escalating budget were being investigated. These included a flat surcharge on income (payroll tax) and VAT while tax deductions for medical schemes were also being considered. 'No one option is deemed to be exclusively desirable but we've told Treasury that we can't go for co-payments, that's out', she revealed. Asked by Izindaba how she characterised the basic differences between herself and Van den Heever, Shisana replied, 'He's an economist looking at social security. I'm coming from the angle of the NHI. While the two might eventually be one in a policy position, they are separate policies. He wants to see social health insurance falling under a social security umbrella and we say, no, the $\mathrm{NHI}$ is run by the national health minister delivering to the health sector. It can't be driven by social security experts; it must be driven by the health sector - that's crucial in terms of consultation'.

She said that only two provinces currently had unqualified audits and that financial improvement plans existed for the other seven while for certain blood products, the NHLS was more expensive than the private sector. On the 'upside', the national health department had received an unqualified audit for the first time in 7 years. 'The area of NHI revenue has not been clearly fleshed out in the ANC's document and will probably be contained in government policy when that comes out. It's the prerogative of the Minister of Finance and work is being done on the macro-economic impact of the NHI, she revealed.

\section{Chris Bateman}

